Dept. of Poultry Diseases.

Animal Health Research Institute,

Sohag Regional Laboratory,

\title{
SOME STUDIES ON PSEUDOMONAS AERUGINOSA INFECTIONS IN PIGEONS IN SOHAG GOVERNORATE
}

(With 3 Tables)

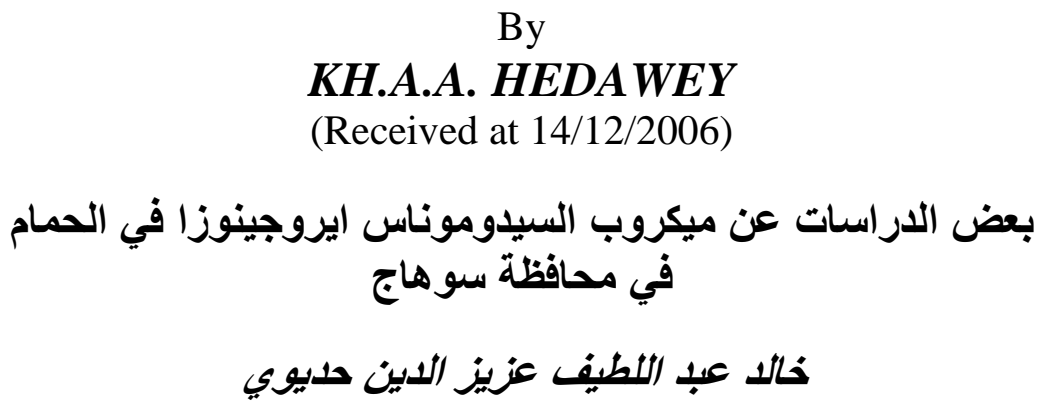

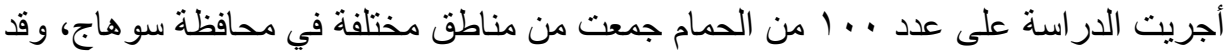

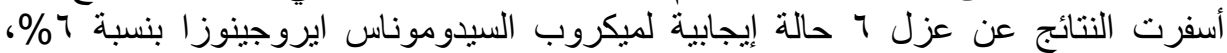

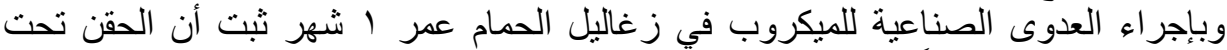

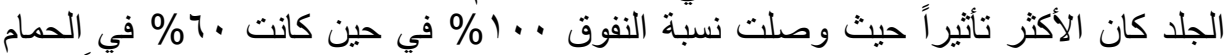

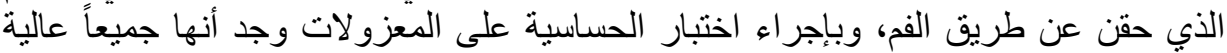

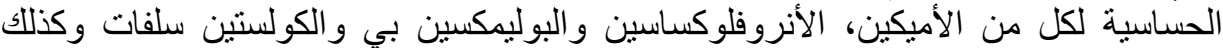

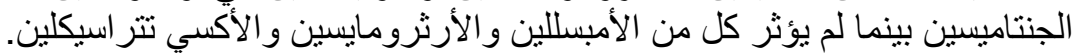

\section{SUMMARY}

In this study 100 cases of pigeons were collected from differents localities at Sohag Governorate. 6 positive cases of Ps.aeruginosa were isolated with an incidence of 6\%. The experimental infection in onemonth-old squabs by different routes showed that subcutaneous route was highly effective with mortality rate $100 \%$, while oral route resulted in $60 \%$ mortality. In vitro antibiotic sensitivity test revealed that the examined isolates were highly sensitive to amikin, enrofloxacin, polymyxin $\mathrm{B}$, colistin sulfate and gentamycin and were resistant to ampicillin, erythromycin and oxytetracyclin.

Key words: Pseudomonas, pigeons. 


\section{INTRODUCTION}

Nowadays, a great attention was payed toward pigeons as a trial to fulfill excessive demands of the increased population from the animal protein. The pigeons meat have known for their good taste and delicacy as well as a suitable source of protein of high biological value. (Casanovas et al., 1995) demonstrated that the fecal bacterial flora of pigeons may be source of infections diseases to man in the city of Barcelona.

Pseudomonas infection of birds are of great importance because epidemics may spread rapidly through poultry flocks causing mortality in all ages, their resistance to different antibiotics make it too difficult to be treated. Also, Pseudomonas aeruginosa is one of the source of serious economic losses and is considered as one of most dangerous diseases which affects poultry industries allover the world. It causes morbidity, mortality and the clinical signs including septicemia, diarrhea and respiratory signs (Saif-Edin, 1983), Shahata et al., 1988 and Tanios and Samia, 1999). Ps. infection in pigeons did not receive much care in our country, therefore the present work was done to give an idea about the following points:

a- Prevalence of Pseudomonas aeruginosa infection among pigeons.

b- Experimental infections using the isolated organisms in pigeons.

c- In vitro sensitivity test of the isolated against different antibiotics.

\section{MATERIALS and METHODS}

\section{1- Samples:}

A total of 100 samples were collected from clinically diseased and freshly dead pigeons of different ages at Sohag province. The collected samples were packed in box and aseptically transferred to the laboratory without delay where they were immediately examined for bacterial isolations.

\section{2- Bacteriological examination:}

The samples were taken aseptically from cloacal, internal organs including liver, heart, spleen, lungs and intestine of clinically diseased and freshly dead pigeons and inoculated in nutrient broth and incubated at $37 \mathrm{C} \dot{\circ}$ for 24 hours then subcultured onto selective Pseudomonas -agar base medium and incubated at $37 \mathrm{C}^{\circ}$ for 24 hours to observe the non lactose fermenting colonies and subcultured onto nutrient agar plate and blood agar to observe the pigmentation and haemolysis. The identification was done according to (Quinn et al., 2002). 


\section{3- In vitro- sensitivity:}

The isolated of Pseudomonas aeruginosa were examined for their susceptibility to the different antibiotics. The paper discs supplied by Bio-Merieux and Oxoid namly Enrofloxacin (10ug), Colistin sulfate (10ug), Amikin(30ug), Flumequine(10ug), Ampicillin(10ug), Erythromycin(15ug), Streptomycin(10ug), Chloramphenicol(10ug), Gentamycin(10ug), Polymyxin B(10ug) and Oxytetracyclin(30ug). The disc diffusion technique of sensitivity to different chemotherapeutic agents were done according to (Finegold and Martin, 1986).

\section{4- Experimental infection:}

A total of thirty, one-month-old pigeons squabs were purchased from the local market, Sohag province were used in this study, squabs were observed and proved to be free from Pseudomonas organism, $3 \times 10^{8}$ colony forming unite adjusted by Macferland density technique of viable identified organism of Pseudomonas aeruginosa (Finegold and Martin, 1986) were inoculated orally and subcutaneous. Symptoms appeared on infected pigeon squabs were recorded. The dead Squabs were undergoes postmortem findings and reisolation of causative agents.

\section{RESULTS}

The clinical signs observed in the diseased pigeons were depressed, respiratory difficulties and diarrhea. While postmortem lesions, general hemorrhages were seen on the surface of the visceral organs. The relative incidence of the recovered Pseudomonas aeruginosa was shown in Table (1), 6 isolates were identified to be Ps.aeruginosa with an incidence of $6 \%$.

The results of antibiogram on the Ps. aeruginosa revealed that amikin, enrofloxacin, polymyxin $\mathrm{B}$, colistin sulfate and gentamycin were the most effective while ampicillin, erythromycin and oxytetracyclin had no effect (Table 2).

As shown in Table (3), the pigeon squabs that infected via s/c revealed death of the most within the first 18 hours while the groups that infected via orally revealed death of 6 pigeon squabs after 24 hours and no symptoms were observed in control group.

Table 1: Incidence of pseudomonas aeruginosa isolates from pigeons.

\begin{tabular}{|c|c|c|c|}
\hline \multirow{2}{*}{ Examined samples } & \multirow{2}{*}{ No. of samples } & \multicolumn{2}{|c|}{ Positive sample } \\
\cline { 3 - 4 } & & No & $\%$ \\
\hline Pigeons & 100 & 6 & 6 \\
\hline
\end{tabular}


Table 2: Shows the results of antimicrobial discs.

\begin{tabular}{|l|c|}
\hline \multicolumn{1}{|c|}{ Antimicrobial agents } & Sensitivity of Ps.aeruginosa isolates \\
\hline Enrofloxacin & +++ \\
\hline Colistin sulfate & +++ \\
\hline Amikin & +++ \\
\hline Flumequine & ++ \\
\hline Ampicillin & - \\
\hline Erythromycin & - \\
\hline Streptomycin & + \\
\hline Chloramphenicol & ++ \\
\hline Gentamycin & +++ \\
\hline Polymyxin B & +++ \\
\hline Oxytetracyclin & - \\
\hline$+++\quad=$ Highly sensitive & \\
$++\quad=$ Moderalty sensitive & \\
$+\quad \quad=$ Weakly sensitive \\
- &
\end{tabular}

Table 3: show the results of experimental infection of pigeon squabs with Ps.aeruginosa $\left(0.5 \mathrm{ml}\right.$ of $3 \times 10^{8}$ c.f.u / ml).

\begin{tabular}{|c|c|c|c|c|c|c|c|c|c|c|c|c|c|c|}
\hline \multirow{2}{*}{$\begin{array}{c}\text { Group } \\
\text { No. }\end{array}$} & \multirow{2}{*}{$\begin{array}{c}\text { No. of } \\
\text { infected } \\
\text { birds }\end{array}$} & \multirow{2}{*}{$\begin{array}{l}\text { Route of } \\
\text { inoculation }\end{array}$} & \multicolumn{10}{|c|}{ Daily death post infection } & \multirow{2}{*}{$\begin{array}{c}\text { Total } \\
\text { No. } \\
\text { of } \\
\text { death }\end{array}$} & \multirow{2}{*}{$\begin{array}{l}\text { Mortality } \\
\text { rate }\end{array}$} \\
\hline & & & 1 & & 3 & 4 & 5 & 6 & 7 & 8 & 9 & 14 & & \\
\hline 1 & 10 & Orally & & 2 & 3 & - & 1 & - & - & - & - & - & 6 & $60 \%$ \\
\hline 2 & 10 & St & 9 & 1 & - & - & - & - & - & - & - & - & 10 & $100 \%$ \\
\hline 3 & 10 & Control & - & - & - & - & - & - & - & - & - & - & & $0 \%$ \\
\hline
\end{tabular}

C. F. $\mathrm{u}=$ colony forming unite

$\mathrm{S} / \mathrm{C}=$ subcutaneous

\section{DISCUSSION}

Pseudomonas aeruginosa is a widely distributed in nature as a non pathogenic microorganism, the saprophytic nature and their widely distribution in different environmental sources and their opportunistic inducing of disease among different birds, although the importance of Pseudomonas aeruginosa infections but no available literature studied the infection of Ps.aeruginosa among pigeons.

In this study, bacteriological examination revealed that the prevalence of Ps.aeruginosa among pigeon samples in a total percentage 6\%. A much lower percentage was reported by (Shahata et al., 1988 and 
Younes et al., 1990) who recovered Ps.aeruginosa from dead growing chickens with an incidence of $4.7 \%$ and $4.6 \%$ respectively. On other hand, (Saif-Edin, 1983 and EL-Shorbagy et al., 2001) isolated Ps.aeruginosa from chickens and quails with an incidence of $21 \%$ and $17.5 \%$ respectively.

The experimental infections in pigeon squabs with Ps.aeruginosa via orally and subcutaneous revealed that, the subcutaneous route of inoculations was the most effective, producing mortality rate $100 \%$ while the oral route induced mortality rate $60 \%$. These results were similar to those recorded by (Shahata, 1981, Saif-Edin, 1983, Shahata et al., 1988, Abdel-Gwad et al., 1998, Tanios and Samia 1999 andELShorbagy et al., 2001) who recorded that Ps.aeruginosa causes $100 \%$ mortality when inoculated subcutaneous in different age of birds.

In vitro antibiogram sensitivity of the Ps.aeruginosa isolates against the different antibiotics, revealed that amikin, enrofloxacin, polymyxin B, colistin sulfate and gentamycin were the most effective while ampicillin, erythromycin and oxytetracyclin had no effect. Similar results were obtained by (Saif-Edin, 1988, Shahata et al., 1988 and EL-Shorbagy et al., 2001).

\section{REFERECES}

Abdel-Gawad, A.M.; Seham, M.A. and Azzaz, H.A. (1998): Some studies on Pseudomonas infections in growing chickens in Assiut farms, Assiut. Vet. Med. J. 38 (76):90-97.

Casanovas, L.; DeSimon, M.; Ferrer, M.D.; Argues, J. and Monzon, G. (1995): Intestinal carriage of Campylobacters, Salmonella, Yrsinias, Pseudomonas and listerias in pigeons in the city of Barcelona.

EL-Shorbagy, M.A.; Mosaad, A.A.; Boushra, M. Hussien and Mervat, M. Abd-Alla (2001): Studies on Ps.aeruginosa infections in Quails. J. Egypt. Vet. Med. Assoc. 61, 1, 205-221.

Finegold, M. and Martin, E.J. (1986): Diagnostic Microbiology $7^{\text {th }}$ Ed. p.p. 186. The C.V.Mosby Company.St.Louis.Toronto. London. Quinn, P.J.; Markey, B.K.; Carter, M.E.; Donelly, W.J.C. and Leonard, F.C. (2002): Veterinary Microbiology and Microbial Disease. MPG Books Ltd, Bodmin, Cornwall U.K.

Saif-Edin, M.EL-Bakry (1983): Some studies on Pseudomonas infection in chickens. M V.Sc. Thesis Fac. Vet. Med. Assiut Univ. 
Shahata, A.B. (1981): Studies on the causes of squab mortality in pigeon lots with special consideration of bacterial agents in Sharkiya province Ph.D. Thesis, Fac.Vet. Med. Zagazig Univ.

Shahata, M.A.; EL-Timawy, A.M. and Sedik, I. (1988): Occurrence of Pseudomonas infection in fowl in Upper Egypt, Assiut. Vet. Med. J. 20 (39):169.

Tanios, A.I. and Samia, M. Kamel (1999): Serovars, Antibiogram and Virulence features of Pseudomonas aeruginosa isolated from chickens Egyptian J. of Comparative Pathol. and Clinical Path.12(1) 1-7.

Younes, J.; Youssef, H.; Abdel-Karim, S. and Hassanein, K. (1990): Epidemiological studies of Pseudomonas aeruginosa in chickens, fish and human. Assiut. Vet. Med. J. 23(45), 48-56. 